\title{
Is accelerated corneal collagen cross-linking for keratoconus the way forward? No
}

Eye (2014) 28, 786-787; doi:10.1038/eye.2014.98; published online 2 May 2014

Collagen cross-linking (CXL) was introduced in the late nineties and was later adopted as a treatment option for keratoconus, pellucid marginal degeneration, and post-LASIK ectasia in $2003 .{ }^{1-3}$ CXL is the only treatment modality for these conditions that addresses the underlying stromal weakening and thus halts disease progression. Recently, accelerated CXL was proposed as an alternative technique, whereby corneal stiffening can be achieved with higher fluence and reduced overall exposure time. ${ }^{4}$

The Bunsen-Roscoe reciprocity law, the basis for accelerated CXL, is valid within a certain range. ${ }^{5}$ Determining what this range is for the cornea and how it translates to treatment settings and outcomes is still not known. Wernli et $a l^{6}$ performed an ex vivo study and found that at illumination intensity of $45 \mathrm{~mW} / \mathrm{cm}^{2}$ and time exposure of $<2 \mathrm{~min}$, no corneal stiffening was achieved. On the basis of the experimental data presented by Richoz et al, ${ }^{7}$ CXL requires the presence of oxygen for corneal stiffening to occur. Time exposure is perhaps more significant than we initially suspected, as at reduced time exposure, where oxygen utilisation is compromised, corneal stiffening is in turn hindered. ${ }^{6,7}$ Moreover, the safety of a higher fluence, even for a short duration, is yet to be demonstrated and there is concern of longterm irradiation toxicity and greater risk of endothelial damage. ${ }^{8,9}$ In the short term, more keratocyte apoptosis has been observed in corneas that have undergone accelerated CXL compared with conventional CXL. ${ }^{10}$ The clinical significance of this is still unknown but suggests that as a procedure, accelerated CXL is harsher to the cornea.
In conventional CXL, a demarcation line, which demonstrates the depth of treatment, is seen at $300-350 \mu \mathrm{m} .{ }^{11}$ A confocal microscopy study by Touboul et $a l^{10}$ showed that with accelerated CXL, the demarcation line lies anterior at an average depth of $100-150 \mu \mathrm{m}$, considerably less than that in conventional CXL. With keratoconus being a posterior corneal disease, at least in its early stages, the CXL depth reached by accelerated CXL may not suffice for effective treatment. ${ }^{12}$ In paediatric patients, treatment with conventional CXL is advocated early before established disease progression, as conventional CXL has been found to be safe and effective. ${ }^{13-15}$ There is no literature available, at least at present, reporting the use of accelerated CXL in paediatric patients.

Perhaps the greatest concern regarding accelerated CXL is that the evidence for its efficacy is powered by case series and small studies, with shorter follow-up than conventional CXL. ${ }^{10,16-18}$ The evidence supporting conventional CXL is extensive, including its successful use in thin corneas $(<400 \mu \mathrm{m})$ with the recommended use of hypoosmolar riboflavin. ${ }^{17-20} \mathrm{O}^{\prime}$ Brart et $a l^{21}$ published long-term results for conventional CXL that reported similar treatment efficacy and safety to the Siena Eye Cross study but also noted that the cornea continues to flatten up to 4 years post treatment. ${ }^{17,18}$ We do not have such studies for accelerated CXL and cannot be certain of its continuing effect. It can be postulated that such an effect of continued flattening may not be observed in accelerated CXL due to its comparatively shallow depth of treatment.

It is clear that accelerated CXL is still in its infancy as the treatment parameters have yet to be defined and standardised. There is great variability in treatment settings across studies 
suggesting that the optimal fluence and timing for accelerated CXL has not been determined. The settings for accelerated CXL differ across studies and also in accordance to the treatment indication. Celik et $a l^{23}$ reported the outcomes of accelerated CXL as an adjuvant treatment to LASIK, using $30 \mathrm{~mW} / \mathrm{cm}^{2}$ for $3 \mathrm{~min}$, whereas Kanellopoulos used a setting of $10 \mathrm{~mW} / \mathrm{cm}^{2}$ for $3 \mathrm{~min}$ as prophylactic treatment in conjunction with LASIK, but used $7 \mathrm{~mW} / \mathrm{cm}^{2}$ for $15 \mathrm{~min}$ in the treatment of keratoconus, ${ }^{16,22}$. More research is needed to determine and standardise the most effective and safe treatment parameters for accelerated CXL. Once this is established, randomised controlled trials would prove invaluable in determining the true efficacy of accelerated CXL and whether accelerated CXL provides at least equal results to conventional CXL.

\section{Conflict of interest}

The authors declare no conflict of interest.

\section{References}

1 Spoerl E, Huhle M, Seiler T. Induction of cross-links in corneal tissue. Exp Eye Res 1998; 66(1): 97-103.

2 Spörl E, Huhle M, Kasper M, Seiler T. Increased rigidity of the cornea caused by intrastromal cross-linking. Ophthalmologe 1997; 94: 902-906.

3 Wollensak G, Spoerl E, Seiler T. Riboflavin/ultravioletA-induced collagen crosslinking for the treatment of keratoconus. Am J Ophthalmol 2003; 135(5): 620-627.

4 Schumacher S, Oeftiger L, Mrochen M. Equivalence of biomechanical changes induced by rapid and standard corneal cross-linking, using riboflavin and ultraviolet radiation. Invest Ophthalmol Vis Sci 2011; 52(12): 9048-9052.

5 Bunsen RW, Roscoe HE. Photochemical researches, part V: on the measurement of the chemical action of direct and diffuse sunlight. Proc R Soc Lond 1862; 12: 306-312.

6 Wernli J, Schumacher S, Spoerl E, Mrochen M. The efficacy of corneal cross-linking shows a sudden decrease with very high intensity UV light and short treatment time. Invest Ophthalmol Vis Sci 2013; 54(2): 1176-1180.

7 Richoz O, Hammer A, Tabibian D, Gatzioufas Z, Hafezi F. The biomechanical effect of corneal collagen cross-linking (CXL) with riboflavin and UV-A is oxygen dependent. Transl Vis Sci Technol 2013; 2(7): 6.

8 Koller T, Mrochen M, Seiler T. Complication and failure rates after corneal crosslinking. J Cataract Refract Surg 2009; 35(8): 1358-1362.

9 Seiler TG, Schmidinger G, Fischinger I, Koller T, Seiler T. Complications of corneal cross-linking. Ophthalmologe 2013; 110(7): 639-644.

10 Touboul D, Efron N, Smadja D, Praud D, Malet F, Colin J. Corneal confocal microscopy following conventional, transepithelial, and accelerated corneal collagen crosslinking procedures for keratoconus. J Refract Surg 2012; 28(11): 769-776.

11 Mazzotta C, Traversi C, Baiocchi S, Caporossi O, Bovone C, Sparano MC et al. Corneal healing after riboflavin ultraviolet-A collagen cross-linking determined by confocal laser scanning microscopy in vivo: early and late modifications. Am J Ophthalmol 2008; 146(4): 527-533.

12 Maguire LJ, Bourne WM. Corneal topography of early keratoconus. Am J Ophthalmol 1989; 108(2): 107-112.

13 Chatzis N, Hafezi F. Progression of keratoconus and efficacy of pediatric [corrected] corneal collagen cross-linking in children and adolescents. J Refract Surg 2012; 28(11): 753-758.

14 Caporossi A, Mazzotta C, Baiocchi S, Caporossi T, Denaro R, Balestrazzi A. Riboflavin-UVA-induced corneal collagen cross-linking in pediatric patients. Cornea 2012; 31(3): 227-231.

15 Vinciguerra P, Albé E, Frueh BE, Trazza S, Epstein D. Two-year corneal cross-linking results in patients younger than 18 years with documented progressive keratoconus. Am J Ophthalmol 2012; 154(3): 520-526.

16 Kanellopoulos AJ. Long term results of a prospective randomized bilateral eye comparison trial of higher fluence, shorter duration ultraviolet A radiation, and riboflavin collagen cross linking for progressive keratoconus. Clin Ophthalmol 2012; 6: 97-101.

17 Caporossi A, Baiocchi S, Mazzotta C, Traversi C, Caporossi T. Parasurgical therapy for keratoconus by riboflavin-ultraviolet type A rays induced cross-linking of corneal collagen: preliminary refractive results in an Italian study. J Cataract Refract Surg 2006; 32(5): 837-845.

18 Caporossi A, Mazzotta C, Baiocchi S, Caporossi T. Long-term results of riboflavin ultraviolet a corneal collagen cross-linking for keratoconus in Italy: The Siena Eye Cross Study. Am J Ophthalmol 2010; 149(4): 585-593.

19 Hafezi F, Mrochen M, Iseli HP, Seiler T. Collagen crosslinking with ultraviolet-A and hypoosmolar riboflavin solution in thin corneas. J Cataract Refract Surg 2009; 35(4): 621-624.

20 Kymionis GD, Portaliou DM, Diakonis VF, Kounis GA, Panagopoulou SI, Grentzelos MA. Corneal collagen cross-linking with riboflavin and ultraviolet-A irradiation in patients with thin corneas. Am J Ophthamol 2012; 153(1): 24-28.

21 O'Brart DP, Kwong TQ, Patel P, McDonald RJ, O'Brart NA. Long-term follow-up of riboflavin/ultraviolet A (370 nm) corneal collagen cross-linking to halt the progression of keratoconus. Br J Ophthalmol 2013; 97(4): 433-437.

22 Kanellopoulos AJ. Long-term safety and efficacy follow-up of prophylactic higher fluence collagen cross-linking in high myopic laser-assisted in situ keratomileusis. Clin Ophthalmol 2012; 6: 1125-1130.

23 Celik HU, Alagöz N, Yikdirim Y, Agca A, Marshall J, Demirok A et al. Accelerated corneal crosslinking concurrent with laser in situ keratomileusis. J Cataract Refract Surg 2012; 38(8): 1424-1431.

$$
\text { C MacGregor }{ }^{1}, \text { M Tsatsos }{ }^{1,2} \text { and P Hossain }{ }^{1}
$$

${ }^{1}$ Southampton Eye Unit, Southampton University Hospitals NHS Trust, Southampton, UK and

${ }^{2}$ Moorfields Eye Hospital NHS Foundation Trust, London, UK

Correspondence: C MacGregor, Southampton General Hospital, Tremona Road, Southampton SO16 6YD, UK

Tel: +44 (0)23 8120 4570;

Fax: +44 (0)238120 4120 .

E-mail: macgregor.cheryl@doctors.org.uk 